\title{
TERCEIRA IDADE, AÇÃO POLÍTICA E AUTONOMIA: AS POLÍTICAS DA VELHICE COMO TECNOLOGIAS SOCIAIS
}

Third age, political action and autonomy: the politics of the oldness as social technologies

Marcos Augusto de Castro Peres*

\section{Resumo}

Este artigo procura analisar as políticas e movimentos sociais da velhice como tecnologias sociais, ou seja, como estratégias de ação política cujo papel seria o de solucionar problemas sociais dos idosos, mas que ocultam técnicas de controle de um grupo social que cresce numericamente, passando a ser interessante do ponto de vista político-eleitoral e mercadológico. A falácia dessas políticas e movimentos é enfatizada pelo fato de que neles não são contempladas demandas emergenciais dos idosos, como a elevação do poder de compra da aposentadoria, por exemplo, tolhendo a sua autonomia.

Palavras-chave: Velhice, movimentos sociais, políticas públicas, autonomia, tecnologias sociais.

\section{Abstract}

The objective of this article is to analyze the politics and social movements of oldness while social technologies, or while strategies to solve problems of the aged, but that hide techniques to control a social group that became interesting to politic and marketing view points. The fallacy of these strategies and movements

\footnotetext{
* Professor Adjunto da Universidade do Estado do Rio Grande do Norte (UERN); mestre em Sociologia pela UNICAMP; doutor em Educação pela USP. Email: mperes@usp.br
} 
te rceira idade, ação política...

is emphasized by the fact of the inexistence of actions to take care of the aged in their primordial demands, such as the increase of the value of retired, for example, harming their autonomy.

Keywords: Oldness, social movements, public politics, autonomy, social technologies.

\section{INTRODUÇÃO}

Este trabalho visa analisar o "movimento social do idoso" no Brasil e as recentes políticas públicas e leis dele resultantes (a Política Nacional do Idoso e o Estatuto do Idoso), sob uma perspectiva crítica, considerando a ausência dos idosos nessas reivindicações e o papel das organizações representativas da velhice (SESC, SBGG, ANG e COBAP) ${ }^{2}$ enquanto as principais protagonistas. Levando em conta que tal "movimento" insere-se num contexto sóciopolítico-demográfico de transformação da velhice em questão social, pretendemos compreendê-lo como um fenômeno análogo às chamadas "redes de movimentos sociais", nas quais observamos um processo de "institucionalização" ou "terceirização" das ações coletivas, coerente à lógica neoliberal de controle das massas e de privatização dos direitos sociais.

Nesta perspectiva, o "movimento social do idoso" - sem a presença do idoso na linha de frente -, bem como as políticas públicas dele resultantes, podem ser entendidos como "tecnologias sociais", cujo papal, aparentemente, é de propor soluções para os problemas sociais que acometem os idosos. Porém, escamoteiam estratégias para controlar um grupo social que cresce rapidamente em virtude do envelhecimento populacional e que, por isso, passa a ser interessante do ponto de vista político-eleitoral e mercadológico. Isso problematiza a idéia de representatividade institucional na medida em que não são contempladas, nestas políticas e ações, demandas primordiais dos idosos, como a elevação do poder de compra da aposentadoria, por exemplo, fazendo com que estes tenham que continuar trabalhando mesmo depois de aposentados para suprir suas necessidades, não podendo 
desfrutar de tempo livre que poderia ser destinado à reflexão e participação política.

\section{OBJETIVOS GERAIS E ESPECÍFICOS}

Esse trabalho tem como objetivo geral analisar a relação entre velhice e autonomia, tendo como base o "movimento social do idoso" protagonizado pelas organizações representativas da velhice no Brasil e as políticas públicas dele derivadas, que, por não mexerem eficazmente na questão da aposentadoria, só fazem perpetuar a alienação política e a sujeição ao trabalho das classes menos favorecidas, mantendo a divisão entre os que podem e os que não podem desfrutar de um tempo livre para a reflexão e participação política. Assim, a autonomia dos idosos, preconizada pelas políticas públicas da velhice, acaba sendo uma autonomia relativa, atrelada à condição de classe.

Portanto, de forma mais detalhada e específica, os nossos objetivos são: (1) analisar o suposto "movimento social do idoso", protagonizado por algumas organizações representativas da velhice no Brasil, principalmente 0 SESC, a SBGG, a ANG e a COBAP, e as recentes políticas públicas e leis de atenção à velhice dele resultantes: a PNI e o Estatuto do Idoso, numa perspectiva crítica, procurando situá-los dentro do contexto de surgimento da velhice como questão social, que, sendo um fenômeno sóciopolíticodemográfico, se dá principalmente à mercê da ação dos próprios idosos; (2) sob a perspectiva da não-participação dos idosos desse "movimento social”, caracterizá-lo como um tipo de tecnologia social, ou seja: "um conjunto de técnicas e processos associados a formas de organização coletiva e estratégias de desenvolvimento capazes de produzir soluções tecnológicas e/ou políticas que contribuam para a inclusão social e melhoria da qualidade de vida”3. Tais ações, contudo, são coerentes à lógica neoliberal de reestruturação produtiva do capital, de globalização econômica e de privatização dos direitos sociais - conforme a interpretação de Montaño (2003) - e dentro da qual pode ser situado o fenômeno de "mercantilização da velhice" presente na idéia de "terceira idade"; (3) mostrar que a exclusão do idoso desse "movimento" reivindicatório por políticas públicas coloca em xeque a questão da representatividade institucional à medida que não 
são contempladas necessidades primordiais desse grupo social, como a elevação do poder de compra da aposentadoria, por exemplo, da qual se eximem tanto a PNI quanto o Estatuto do Idoso; e (4) por fim, analisar o trabalho no pós-aposentadoria como um cerceamento da autonomia dos idosos, que os impede de desfrutar do tempo livre depois de uma vida toda explorada pelo trabalho alienado. Tempo esse que poderia ser destinado à reflexão e à participação política, enfim, à efetiva prática da autonomia.

\section{ASPECTOS METODOLÓGICOS}

No desenvolvimento da pesquisa utilizamos três tipos de fontes para a obtenção de dados/informações: 1) pesquisa bibliográfica, 2) análise documental e 3) entrevistas. Pretendemos tratar do tema proposto tendo como principal ponto de partida o suposto "movimento social do idoso" no Brasil, e as políticas públicas dele resultantes: PNI e Estatuto do Idoso, procurando levar em conta a ação das organizações representativas da velhice consideradas na análise: SESC, SBGG, ANG e COBAP, que figuram entre as principais protagonistas desse "movimento" no Brasil, conforme mostra Belo (2002), e que tiveram papel decisivo na transformação da velhice em questão social. A principal problemática considerada foi a não-participação do idoso desse "movimento", fato que é identificado claramente pela pesquisa de Santos (1998), e que coloca em cheque tanto a integridade da ação das organizações representativas da velhice, quanto a idéia de representatividade institucional, além de lançar dúvidas sobre a eficiência das recentes políticas públicas voltadas ao idoso, que não atendem necessidades básicas como a elevação da renda da aposentadoria, um direito social do trabalhador, causando o fenômeno do trabalho no pósaposentadoria.

Procuramos, assim, estudar a problemática inicialmente com levantamento bibliográfico acerca de temas fundamentais, como: a construção social da velhice, velhice e capitalismo, a idéia de terceira idade, o envelhecimento populacional, os antigos e novos movimentos sociais, o debate sobre a centralidade do trabalho, o terceiro setor e a institucionalização/terceirização das ações coletivas, o neoliberalismo, a globalização, a reestruturação produtiva, a democracia representativa, as 
políticas sociais, a aposentadoria e o trabalho dos idosos enquanto prática de resistência e subjetividade.

A análise documental privilegiou a consulta de documentos pertinentes: 1) à ação das organizações representativas da velhice na demanda por políticas públicas; 2) à obtenção de privilégios e interesses particulares/ corporativos por parte dessas organizações; 3) à exclusão dos idosos do "movimento social" que afirma lutar pela cidadania, autonomia e integração desse grupo social; 4) às estratégias de controle e tutela exercidas pelas organizações representativas da velhice frente a um dos segmentos da população que mais cresce na atualidade em virtude do envelhecimento populacional no Brasil; 5) às ações dessas organizações referentes à aposentadoria e à Previdência Social, exatamente a parte mais falha e tímida tanto na PNI quanto no Estatuto do Idoso, políticas que afirmam ter por objetivo, contraditoriamente, promover a autonomia do idoso. Pretendemos analisar diversos tipos de documentos, tais como: regimento interno das organizações, seus planos de ação e programas relacionados às políticas públicas, leis e artigos componentes da PNI e do Estatuto do Idoso, ou a eles relacionados, manifestações, memorandos, circulares referentes ao Fórum Regional da PNI no Rio de Janeiro, organizado pela ANG. O nosso lócus de investigação foi: as próprias organizações, os eventos por elas promovidos e o Conselho Nacional dos Direitos do Idoso. ${ }^{4}$

Nas entrevistas, coletamos os discursos: 1) dos membros estratégicos das organizações representativas da velhice (mínimo de um por organização), referentes às ações em prol da cidadania e integração dos idosos, que constam da PNI, focando essencialmente a questão da autonomia. ${ }^{5}$ Assim, ao debatermos sobre a aposentadoria, buscamos identificar as oposições de sentido e contradições presentes nos discursos dos entrevistados, seguindo o caminho apontado por Schein (1992) relativo à análise dos pressupostos inconscientes ${ }^{6} ; 2$ ) dos aposentados que podem participar dos fóruns de debate promovidos pelas organizações representativas da velhice (em média quatro); 3) dos aposentados que ainda desenvolvem trabalho remunerado (em média quatro), questionando-os acerca da necessidade de trabalhar em virtude da precariedade dos benefícios previdenciários pagos pelo Estado, bem como acerca das políticas públicas de atenção 
à velhice, enfocando a questão da aposentadoria. Procuramos identificar na fala desses idosos as práticas de subjetividade, resistência e autonomia real - no sentido apontado por Guattari (1987) - verificadas no plano da consciência, ou seja, na crítica feita por eles ao Estado ${ }^{7}$, à burocracia das organizações representativas da velhice e à lógica de exclusão que permeia a sociedade capitalista, que não garante autonomia aos trabalhadores após a aposentaria. ${ }^{8}$

\section{O CENÁRIO SÓCIOPOLÍTICO E AS NOVAS PERSPECTIVAS DA VELHICE NO BRASIL}

\section{A aposentadoria e o surgimento da "terceira idade"}

É interessante notarmos que, com o aumento do número de aposentados decorrente do envelhecimento populacional, principalmente a partir da década de 1980, o Estado, as classes empresariais e a comunidade científica começariam a dar maior atenção à questão da velhice, a nível mundial. O Estado passa a querer se livrar do ônus referente ao crescente aumento de benefícios previdenciários a serem pagos aos trabalhadores ${ }^{9}$ e, ao mesmo tempo, controlar um contingente eleitoral cada vez mais expressivo (RAMOS, 2001). Os empresários estariam atentos ao novo filão de mercado consumidor que se projetava, cujos integrantes conciliavam tempo livre e renda para o consumo (DEBERT \& SIMÕES, 1998). Os especialistas em gerontologia/geriatria, por sua vez, procurariam delimitar e legitimar o seu campo de atuação na sociedade (LOPES, 2000).

Sabe-se que os direitos sociais e trabalhistas, dentre os quais a aposentadoria, foram sendo incorporados ao Estado em virtude das pressões exercidas pelos movimentos de trabalhadores. Isso fez com que o Estado aumentasse de tamanho, necessitando trazer para si funções destinadas ao bem-estar da sociedade. Com a ofensiva neoliberal verifica-se um processo de desmonte desse "Estado social". A reestruturação produtiva, a automação, a flexibilização dos direitos trabalhistas e o desemprego estrutural serviriam para desmobilizar e enfraquecer os movimentos operário e sindical de épocas anteriores, deixando livre o caminho para o Estado se desresponsabilizar dos custos com o social. Dessa forma, os direitos sociais 
passam a ser privatizados. Desenvolve-se um mercado de planos privados de saúde e de previdência, assim como proliferam as escolas particulares, as empresas de turismo e lazer e a própria assistência social passa a ser privatizada, surgindo as organizações não-governamentais (ONGs) para desempenharem essa função (MONTAÑO, 2003).

Ademais, o aumento do número de idosos seria também do interesse do Estado democrático à medida que estes passam a significar uma considerável massa de eleitores. Talvez isso explique porque a Constituição de 1988 no Brasil dedicou uma atenção especial à velhice, tratandoa como direito humano fundamental e incluindo, pela primeira vez numa constituição brasileira, leis referentes à assistência social e à previdência social, além de proibir qualquer forma de discriminação baseada na idade. (RAMOS, 2001). É interessante notar, como destaca Ramos (2001), que a velhice já havia se tornado, quando da promulgação da Constituição de 1988: "temática a merecer ações responsáveis direcionadas a assegurar os direitos fundamentais das pessoas pertencentes a essa faixa etária”(213).

Coerente aos propósitos privatistas do Estado neoliberal, conforme mostram Debert \& Simões (1998), forma-se um mercado voltado para a velhice, onde observamos o surgimento de inúmeras empresas de previdência privada (ligadas aos bancos), de saúde, reabilitação ou rejuvenescimento, de lazer/turismo e de educação (universidades da terceira idade), todas elas especializadas em serviços destinados aos idosos aposentados, principalmente àqueles de maior poder aquisitivo, que além de disporem de maior tempo livre, tinham maior potencial de consumo que os idosos de classe baixa. Bobbio (1997) ilustra essa situação da seguinte forma: "Em uma sociedade de consumo onde tudo pode ser comprado e vendido, onde tudo tem um preço, também a velhice pode se transformar em uma mercadoria” (p. 25).

É neste contexto que surgem a geriatria e a gerontologia como especialidades científicas, delimitando como objeto de estudo a velhice e o envelhecimento. De acordo com Lopes (2000): "O ano de $1982^{10}$ pode ser considerado o marco internacional da legitimação da gerontologia como campo de saber multidisciplinar autorizado a tratar das questões do envelhecimento" (p. 39). Os especialistas em gerontologia e geriatria 
passariam, assim, a ser os agentes sociais encarregados do "gerenciamento da velhice", detendo o monopólio da autoridade científica sobre as questões referentes ao processo de envelhecimento, bem como o poder social (e político) de opinar, conduzir e interferir em tais questões (LOPES, 2000).

Tanto a atenção do Estado referente ao envelhecimento da população, quanto o surgimento de um "mercado da velhice" e da geriatria/gerontologia como especialidades científicas contribuiriam ativamente para a invenção do termo conhecido como "terceira idade". Originária na França, na década de 1970, essa expressão surge a partir da criação das Universidades da Terceira Idade (Universités du Troisième Age), sendo incorporada posteriormente pelo vocabulário anglo-saxão, com a criação das Universities of the Third Age em Cambridge, na Inglaterra, em 1981 (LASLETT, 1987). O termo universalizou-se rapidamente nos países que apresentavam um relativo envelhecimento da sua população, tendo o Serviço Social do Comércio (SESC) papel primordial na popularização da expressão "terceira idade" no Brasil, através da implantação, no início da década de 1980, das primeiras Universidades Abertas à Terceira Idade (CACHIONI, 1999).

Contudo, a criação das Universidades Abertas à Terceira Idade (UNATI) no Brasil carrega um grande paradoxo quando consideramos o alto índice de analfabetismo entre os idosos no País. Segundo dados do IBGE do Censo 2000, 34,6\% do total dos brasileiros (homens e mulheres) com 60 anos ou mais são analfabetos. Tal fato reforça o caráter elitista das UNATI, bem como o forte ranço burguês presente na idéia de "terceira idade". Com isso, cabe lançar a seguinte questão: qual a validade de se investir na criação de "universidades para idosos" num país que necessita urgentemente de políticas de educação fundamental para todas as faixas etárias?

Parece que a própria origem da expressão "terceira idade”, ligada à criação das UNATI, reflete o caráter paliativo inerente a determinadas políticas públicas, que ao invés de estarem direcionadas à solução efetiva dos problemas sociais, em seus aspectos mais emergenciais, restringem-se a medidas superficiais, que muitas vezes não suprem as reais necessidades dos destinatários das políticas sociais, pois estes raramente participam do 
professo de formulação dessas políticas. São as organizações representativas dos diversos grupos sociais, em conjunto com nossos representantes políticos dos poderes Legislativo e Executivo, nas esferas federal, estadual e municipal, que de fato elaboram as políticas sociais, muitas vezes à mercê das demandas efetivas da sociedade (VIEIRA, 1987).

Da mesma forma, observa-se que o surgimento do termo "terceira idade" não ocorreu em virtude da iniciativa dos próprios idosos de criarem para si uma denominação nova e menos pejorativa do que a de "velho", mas envolveu uma multiplicidade de agentes cuja função específica era tratar da velhice, fazendo com que essa adquirisse uma visibilidade social cada vez maior (DEBERT, 1997). Isso nos leva a crer que o fato de a velhice estar se transformando hoje em questão social, em diversos países do mundo e no Brasil, não decorre somente do aumento do número de idosos e da condição de marginalidade ou exclusão social vivida por muitos deles, mas também e principalmente da "mercantilização da velhice" presente na idéia de "terceira idade".

\section{Um "movimento social do idoso"... sem o idoso?}

Ao considerarmos os três elementos principais que levaram a velhice a ganhar visibilidade pública e a emergir enquanto uma questão social relevante na sociedade contemporânea - em síntese: o envelhecimento populacional, a exclusão social vivida pelos idosos e o surgimento da aposentadoria e dos agentes e instituições especializadas na velhice -, é necessário atentar para o fato de que foi principalmente a partir da ação - ou pressão, no sentido dado por Lénoir (1989) - dos atores sociais encarregados da questão da velhice que esta passa a adquirir reconhecimento (visibilidade social), legitimação (atenção da sociedade) e novas formas de expressão ("terceira idade").

Contudo, deve-se perceber também que ao se considerar a velhice como uma questão social está-se referindo não só à importância e à visibilidade que esta adquire perante a sociedade, mas, fundamentalmente, à atenção que o Estado passa a dar a ela (COHN, 2000). Assim, o envelhecimento populacional e o aumento do número de idosos, bem como a exclusão social vivida por eles, não são os únicos fatores responsáveis 
pela recente atenção do Poder Público com relação às questões pertinentes à velhice, tanto no Brasil como em diversos países do mundo, tal como querem fazer crer os formuladores de políticas públicas. ${ }^{11}$ Essa atenção depende principalmente da rearticulação de interesses e demandas políticomercadológicas empreendida pelas organizações representativas da velhice (DEBERT, 1997).

Ademais, conforme destaca Belo (2002), a atenção política dada à questão da velhice insere-se numa perspectiva internacional de ação, tendo a Organização das Nações Unidas (ONU) como a principal promotora, que passa a fundamentar suas ações no envelhecimento da população mundial. A “I Assembléia Mundial sobre o Envelhecimento", realizada em Viena em 1982, adota o "Plano de Ação Internacional" que se constitui na base das políticas públicas elaboradas para este grupo de população. Um conjunto de ações, portanto, seguem-se. Em 1991 a ONU aprova os princípios a favor das pessoas idosas em torno de cinco eixos: independência, participação, cuidados, autorealização e dignidade. O ano de 1999 é nomeado pela ONU como "Ano Internacional do Idoso", instituindo como tema: "Uma sociedade para todas as idades”, em referência à necessidade de inserção social dos idosos. Em 2002 se realiza a "II Assembléia Internacional sobre o Envelhecimento", na Comunidade Européia, que conta com a presença da Organização Internacional do Trabalho (OIT) e vem reforçar o conceito de envelhecimento ativo, fundado nas idéias de produtividade e qualidade de vida e coerente aos princípios ideológicos da "terceira idade" (BELO, 2002).

No Brasil, o "plano de ação" referente à velhice passa a ser protagonizado, conforme mostra Belo (2002), por um conjunto de organizações da sociedade civil, cujos principais representantes são: 1) o Serviço Social do Comércio (SESC), especializado no atendimento ao idoso nas áreas de lazer, cultura e educação, tem uma produção bibliográfica considerável sobre a velhice e o envelhecimento e figura como o pioneiro na promoção da Universidade Aberta à Terceira Idade no Brasili12; 2) a Sociedade Brasileira de Geriatria e Gerontologia (SBGG), entidade de natureza técnico-científica, composta por médicos e gerontólogos, autointitula-se como uma das pioneiras na "frente de defesa do idoso", promove 
cursos, simpósios e congressos visando difundir os conhecimentos acerca dos processos biológicos e sociais do envelhecimento ${ }^{13}$; 3) a Associação Nacional de Gerontologia (ANG), também de natureza técnico-científica, é composta por gerontólogos sociais e tem por objetivo despertar a consciência gerontológica na sociedade em prol de melhorias nas condições de vida dos idosos. A entidade conta com publicações próprias e promove o Fórum Permanente da Política Nacional do Idoso ${ }^{14}$; e 4) a Confederação Brasileira de Aposentados e Pensionistas (COBAP), uma entidade organizada de aposentados, em sua maioria sindicalistas, que se auto-define como: "uma autêntica e legítima entidade representativa desse segmento social no país"16. Procura conscientizar os aposentados e pensionistas acerca dos problemas referentes à Previdência Social no Brasil e atua junto ao Poder Público por meio de articulações e lobbies políticos. ${ }^{16}$

Essas organizações compõem a "linha de frente" da luta pelos direitos dos idosos e têm atuado no sentido de dar visibilidade à questão da velhice na sociedade brasileira e reivindicar, junto ao Estado, políticas públicas de atenção a esse grupo etário. Tiveram papel decisivo na elaboração e implementação da Política Nacional do Idoso (PNI), disposta através da Lei 8.842, de 04 de janeiro de 1994 e regulamentada em 03 de julho de 1996. Sua atuação também foi intensa na criação e aprovação do Conselho Nacional dos Direitos do Idoso (CNDI) ${ }^{17}$, em 13 de maio de 2002, que integrava a proposta original da PNI e foi vetado pelo governo FHC em 1996, e no qual tomam acendo membros dessas entidades. A mais recente conquista viabilizada pela ação das entidades representativas da velhice foi a consolidação do Estatuto do Idoso em 2003. ${ }^{18}$

Se a PNI tem por objetivo: "assegurar os direitos sociais do idoso, criando condições para promover sua autonomia, integração e participação efetiva na sociedade" 9 , o CNDI, por sua vez, terá o papel de: "supervisionar e avaliar a PNI"20, bem como de: "zelar pela participação de organizações representativas dos idosos na implementação de políticas, planos, programas e projetos de atendimento ao idoso"21. Quanto ao Estatuto: “discorre sobre os direitos do idoso e seus fundamentos éticos e legais, bem como aborda a responsabilidade das entidades de atendimento aos idosos, transpondo para a prática os princípios expostos na PNI" ${ }^{22}$ 
Esse conjunto de legislações e políticas públicas referentes à velhice representam "planos de ação" do governo brasileiro que, seguindo uma tendência mundial, procuram estabelecer estratégias de combate à exclusão social vivida por muitos idosos, incluindo-os e integrando-os à sociedade. Essa é a idéia-chave do discurso proferido tanto pelos organismos internacionais quanto pelo Estado e pelas organizações representativas da velhice no Brasil, ao procurarem justificar as suas ações "em prol" dos idosos (SANTOS, 1998).

Contudo, um fato em particular é bastante curioso nesse processo: a ausência quase completa dos próprios idosos em meio às ações que visam promover a sua cidadania. São as organizações representativas da velhice, e não os idosos, que têm se mobilizado no sentido de solicitar ações do Estado. Ao entrevistar membros do Conselho Estadual do Idoso do Estado de São Paulo, Santos (1998) revela a não-participação dos idosos na reivindicação por políticas públicas. Um dos entrevistados afirma o seguinte: "Mas a grande crítica que eu faço ainda é ao nível extremamente baixo do envolvimento da população idosa com relação à PNI. (...) É um segmento que acostumou a esperar que medidas venham de 'cima para baixo' e que não teve a oportunidade de exercitar a capacidade de organização e reivindicação necessária (...). Eles se retiram desse cenário porque não tiveram oportunidade de ser protagonistas ao longo da história” (p. 76). Outro entrevistado também se refere à falta de participação dos idosos: "Os idosos ainda não sabem que são parte viva da sociedade, eles mesmos se excluem” (p. 79).

A partir dos depoimentos, percebe-se que a exclusão do idoso do processo de reivindicação por políticas públicas é clara. Neste sentido, Santos (1998) afirma que: "O aspecto negativo mais presente a falta do comprometimento e da participação dos idosos, apontada por todos os entrevistados” (p. 79). Também Neri (2003) destaca a ausência do idoso desse processo, afirmando que: "pessoas oriundas do SESC, da SBGG e profissionais engajados na defesa dos direitos dos idosos que, por muitos anos, fizeram lobby junto a políticos, agregaram pessoas, promoveram discussões e eventos e levantaram publicamente a questão da velhice, mostrando à sociedade que esse é um tema digno de merecer investimentos. 
Ninguém a citar nominalmente, mas simplesmente eu quis dizer que não houve uma pressão organizada proveniente dos idosos. Sobre os Conselhos [de idosos], há vários tipos de inserção e várias formas de organização, mas os idosos não estão na linha de frente" (informação verbal). ${ }^{23}$

Conforme já mostramos, a própria transformação da velhice em questão social, à medida que desperta a atenção do Estado, passa longe de ser conseqüiência da ação política dos idosos, mas é resultado de um processo sóciopolítico que tem as organizações representativas da velhice como as principais protagonistas. No entanto, nota-se no discurso dessas organizações uma referência freqüente a um "movimento social do idoso". Observe-se, por exemplo, o "Manifesto do Fórum Permanente da PNI" do Rio de Janeiro, organizado pela ANG: "O Fórum, em sua reunião ordinária (...) deliberou por manifestar sua indignação quanto ao decreto (...) aprovado pelo Presidente da República, tendo em vista que o mesmo foi conduzido sem atender à Lei 8.842 e o desejado pelo Movimento Social do Idoso". ${ }^{24}$

Também entre os membros do governo responsáveis pela gestão da PNI é possível notar uma referência quanto ao papel do idoso num suposto "movimento" reivindicatório por políticas públicas. Escrevendo sobre as políticas do Ministério da Justiça que integram a $\mathrm{PNI}^{25}$, Barros (1999) salienta que: "os idosos também são responsáveis pelo direcionamento da ação do governo; na medida em que mais se organizarem, suas vitórias serão maiores; suas carências serão supridas e seus direitos serão respeitados" (p. 53). ${ }^{26}$ A própria PNI se refere a um "movimento do idoso": "Na área de cultura, esporte e lazer [pretende-se] incentivar os movimentos de idosos a desenvolver atividades culturais". ${ }^{2}$

Se o "movimento social do idoso" aqui referido não é, na verdade, protagonizado pelos idosos, mas sim por uma rede de atores sociais envolvidos com a questão da velhice, ele se assemelha ao que SchererWarren (2002) chama de "rede de movimentos sociais". Tais "redes" representam a nova tendência observada atualmente nos movimentos sociais, ${ }^{28}$ que aglutinam um conjunto de atores, dentre os quais destacamse as organizações não-governamentais (ONGs) e outras entidades da sociedade civil - como entidades científicas, clubes e associações diversas 
-, nacionais e internacionais, num processo de institucionalização das ações coletivas, que ocorre simultaneamente à globalização da economia e ao fenômeno de reestruturação produtiva do capital (MONTAÑO, 2003).

Se o movimento operário do início do século XX e os movimentos feminista e negro que ocorrem a partir da década de 1950 eram protagonizados efetivamente pelos trabalhadores, pelas mulheres e pelos negros, hoje são as organizações representativas desses grupos que agem por eles, numa espécie de "terceirização" da defesa da cidadania (MONTAÑO, 2003). Parece haver uma cooptação ${ }^{29}$ por parte do Estado, das ONGs e das demais entidades que compõem o chamado "setor social" ou "terceiro setor" 30 , das ações reinvindicatórias que eram praticadas anteriormente pelas camadas populares contra a exclusão. O embate capital/trabalho, dos trabalhadores contra as classes proprietárias e 0 Estado, passa a ser substituído pelas parcerias e acordos. Nesse contexto, os direitos trabalhistas e sociais conquistados a duras penas pela classe trabalhadora passam a ser gradativamente privatizados e flexibilizados (MONTAÑO, 2003).

Esse mecanismo de cooptação se torna claro quando observamos como a PNI incita os idosos à participação política: "o idoso deve ser $o$ principal agente e o destinatário das transformações a serem efetivadas através dessa política”. ${ }^{31}$ Conforme afirma Demo (1995), quando o Estado estimula a participação, isso é no mínimo suspeito, pois provavelmente está escamoteando estratégias de controle e tutela dos grupos sociais envolvidos. E é exatamente isso o que parece estar acontecendo com as recentes políticas de atenção ao idoso. Note-se, por exemplo, que dentre as diretrizes da PNI inclui-se a: "participação do idoso, através de suas organizações representativas, na formulação, implementação e avaliação das políticas, planos, programas e projetos a serem desenvolvidos" ${ }^{32}$ Podese ver claramente como a PNI privilegia as organizações representativas da velhice, principalmente o SESC e as entidades de gerontologia/geriatria, concedendo-lhes o monopólio da representação e da participação nas questões referentes ao idoso no Brasil (SANTOS, 1998).

Por outro lado, é interessante observar como a parte referente à previdência social - exatamente aquela que representa um dos principais 
direitos do trabalhador e na maioria das vezes a sua única fonte de renda na velhice ${ }^{33}$ - é demasiadamente tímida e fraca tanto na PNI quanto no Estatuto do Idoso. Por exemplo, estabelece-se como competência dos órgãos e entidades públicos, na implementação da PNI, na área de previdência social, somente os seguintes aspectos: "priorizar o atendimento ao idoso nos benefícios previdenciários" e: "criar e estimular a manutenção de programas de preparação para aposentadoria” ${ }^{34}$ Nota-se que também o Estatuto do Idoso: "foi tímido no Capítulo VII (Previdência Social), pois não incluiu medidas salariais que viessem suavizar o dia-a-dia do aposentado idoso" ${ }^{35}$

Conforme mostra o Boletim Estatístico da Previdência Social do ano de 2003, 65\% da totalidade de aposentados no Brasil recebe um salário mínimo de renda, e 12,5\% recebem de um a dois salários mínimos. Considerando o baixíssimo poder de compra do salário mínimo dentro da economia brasileira, ${ }^{36}$ fica clara a situação de precariedade social vivida por muitos idosos no País, a qual as recentes políticas públicas parecem não apresentar soluções eficazes na medida em que se eximem nos aspectos referentes à melhoria da renda previdenciária, tida como condição primeira para a autonomia e integração do idoso à sociedade (CAMARANO, 1999).

A ênfase em aspectos secundários de "inclusão", como o acesso gratuito a transportes públicos, cinemas e outras atividades culturais e de lazer, dada pela PNI e pelo Estatuto do Idoso, vêm na verdade apresentar medidas paliativas para o problema da exclusão do idoso da sociedade. Fazendo isso, o Estado foge da responsabilidade e dos gastos que teria com a melhoria da renda previdenciária (HADDAD, 2001). O depoimento de uma idosa aposentada, de 65 anos, ilustra bem o caráter contraditório das políticas públicas da velhice: "Sou aposentada e me mantenho, exclusivamente, com a merreca que recebo do INSS. (...) Se o idoso tivesse um benefício de acordo com o valor contribuído para a sua aposentadoria, não precisaria passar pelo constrangimento de esmolar uma sessão de cinema". ${ }^{37}$

Sendo assim, o suposto "movimento social do idoso", sem o idoso, passa a resultar na formulação de políticas públicas que não atendem 
às reais necessidades desse grupo social. Vieira (1987) explica esse fenômeno afirmando que: "A política social desde 1964 reduziu-se a uma série de decisões setoriais na Educação, na Saúde, na Previdência Social e na Assistência Social, servindo geralmente para desmobilizar as massas carentes da sociedade. Ela ofereceu serviços sem antes perguntar quais eram as necessidades reais. Duvida-se de que isso se chame de política social" (p. 232). É interessante notar como o perfil

\section{DESCRIÇÃO DOS RESULTADOS}

\section{As políticas da velhice como tecnologias sociais}

É interessante observarmos como as políticas públicas da velhice analisadas aqui podem ser compreendidas como tecnologias sociais, na medida em que representam estratégias de ação com o objetivo de solucionar os problemas sociais que acometem a população idosa. As intervenções das organizações de gerontologia e geriatria - tanto na elaboração de políticas públicas como de ações coletivas relativas à velhice -, por se fundarem num caráter essencialmente científico (enquanto "ciências da velhice"), podem ser exemplos evidentes de tecnologias sociais. Haddad (1986) mostra como as políticas estatais no âmbito da terceira idade passaram a se delinear, a partir da década de 1980, com base, principalmente, nos discursos sobre a velhice produzidos pela gerontologia. $\mathrm{O}$ mesmo vale para o SESC e as associações de aposentados, que também tiveram participação efetiva na elaboração do Estatuto do Idoso e da Política Nacional do idoso. Os interesses dessas organizações estão, em grande medida, contemplados nessas políticas. O mesmo não ocorre com interesses emergenciais da população idosa, como a elevação do poder de compra da aposentadoria, por exemplo, que ignorada nessas políticas (cf. PERES, 2007).

O Estado neoliberal, dessa forma, elabora tecnologias sociais que, na forma de políticas públicas, aparentam uma preocupação com os problemas sociais mais urgentes, mas que, na verdade, escamoteiam estratégias de controle e dominação. Conforme destacam Sánches \& Martínez (2006), não podemos entender o neoliberalismo unicamente como modelo sócioeconômico, mas como uma tecnologia social ou de governo que produz 
discursos, identidades e ações, que aparentemente defendem a autonomia dos indivíduos, mas que na verdade a anulam. Dessa forma: "Oneoliberalismo requer sujeitos ativos, auto-responsáveis e "empresários de si próprios" e os discursos e práticas psicológicos participam na elaboração de códigos morais que enfatizam esse ideal de autonomia responsável" (p. 7).

\section{Qual autonomia?}

Diante desse cenário neoliberal, pode-se questionar o seguinte: como é possível ao idoso ter autonomia sendo que o próprio Estado tolhe essa autonomia restringindo a principal fonte de renda dos idosos (a aposentadoria) e atribuindo às organizações representativas da velhice 0 papel de controlar a participação deles na vida política e na construção da sua própria identidade? Que autonomia é essa que quer garantir a PNI, sendo que não permite nem mesmo que 0 idoso se manifeste autonomamente sobre as suas reais necessidades?

Tal raciocínio coloca em xeque tanto a idéia do Estado como representante dos interesses da população, quanto a própria noção de representatividade, da qual se servem as organizações da velhice, na mesma lógica dos partidos políticos e sindicatos, que utilizam um discurso pseudorevolucionário de defesa dos oprimidos. ${ }^{38} \mathrm{~A}$ sociedade burocrática que emerge com o capitalismo industrial traz um contexto em que as decisões político-econômicas e empresariais passam a ser tomadas pelas cúpulas hierárquicas. $\mathrm{O}$ discurso da democracia representativa ${ }^{39}-$ de que as bases têm poder de decisão - é utilizado pelo capitalismo burocrático como estratégia de dominação, controle e passivização das massas populares, conforme defendem Dias (1999) e Tragtenberg (1980), dentre outros. ${ }^{40}$

Isso nos faz pensar sobre o papel da COBAP enquanto entidade ligada ao sistema sindical e que se autodefine como defensora legítima dos direitos dos aposentados. Essa organização representativa da velhice teve atuação fundamental no movimento dos aposentados das décadas de 1980/90, fazendo lobby político e organizando manifestações que ganharam grande repercussão pública na época, conforme mostram Haddad (2001) e Simões (2000). Teve um papel importante também na elaboração e aprovação do Estatuto do Idoso em 2003. ${ }^{41}$ Contudo, como explicar, por 
exemplo, a já comentada timidez dos artigos referentes à Previdência Social nesse Estatuto? Isso lança dúvidas sobre a atuação "revolucionária" dessa organização especializada na questão previdenciária, que parece privilegiar interesses particulares de cunho político-eleitoral. ${ }^{42}$

Para Motta (1986), a autonomia é a única alternativa revolucionária e desenvolve-se necessariamente no âmbito da prática cotidiana dos indivíduos e dos seus discursos de contestação à ordem. $\mathrm{O}$ autor defende que o mais importante é: "a autotransformação social, que se refere ao fazer social e político dos homens na sociedade e nada mais. $O$ fazer pensante e $o$ pensar político implicam-se numa unidade indestrutível (...). E este fazer-se é o contrário das hierarquias burocráticas" (p. 28).

Neste sentido, sabe-se que a precariedade dos benefícios previdenciários obriga muitos aposentados a continuarem trabalhando, seja para garantir a sobrevivência própria ou da família, ou para evitar quedas violentas do padrão de vida, conforme é mostrado por Camarano (1999). E é na necessidade de continuar trabalhando após a aposentadoria que se tornam claros a sujeição e o aprisionamento dos trabalhadores por um sistema que não permite a liberdade. A reflexão, o "pensar político" e o "fazer pensante", parafraseando Prestes Motta (1986), são as reais práticas de autonomia. Essa liberdade de reflexão - ou seja, a prática do ócio reflexivo ou criativo - é retirada dos aposentados que necessitam trabalhar.

\section{CONCLUSÃO}

Portanto, é na possibilidade de debaterem as políticas públicas que lhes dizem respeito, nos fóruns de discussão ou mesmo em outros âmbitos da vida cotidiana, que se expressam práticas de resistência, subjetividade e autonomia real entre os idosos. Assim, a crítica dos idosos tanto às políticas da velhice quanto à participação restrita e limitada oferecida pelo atual modelo de democracia, bem como à exploração do trabalho que lhes cerceia a liberdade, constituem micropoderes potencialmente "revolucionários", porque se opõem à lógica de controle burocrático inerente ao capitalismo, dentro de uma dimensão "molecular", na concepção de Guattari (1987) ou "micropolítica", na definição de Foucault (1999). Tais práticas de 
resistência, por ocorrerem no plano da subjetividade e da vida cotidiana dos indivíduos, passam despercebidas numa sociedade fundada na lógica institucional. Segundo essa lógica, tudo deve ser institucionalizado. Isso ocorre, até mesmo, com as práticas "revolucionárias" vigentes até então, protagonizadas pelos partidos de esquerda, sindicatos e demais organizações representativas de categorias ou grupos sociais.

Contudo, todas essas alternativas se encontram capturadas pela lógica burocrática. São, essencialmente, tecnologias sociais, de cunho neoliberal. Por isso, qualquer forma de resistência que seja realmente autônoma deve ocorrer fora dessa lógica e, principalmente, opondo-se a ela. Conforme afirma Dallari (1984): "A atitude de resistência é sempre possível no plano da consciência” (p. 54). Sem exagero, poderíamos dizer que a resistência que ocorre no plano da consciência é, na verdade, uma das únicas formas efetivamente possíveis dentro da atual ordem do capital, caracterizada pelos mecanismos de controle e vigilância institucional, que se encontram muitas vezes ocultos sob a aparência falaciosa da "boa intenção".

\section{NOTAS}

1 Doutor em Educação pela USP. Mestre em Sociologia pela UNICAMP. Professor Adjunto do Centro Universitário UNIARARAS.

2 SESC - Serviço Social do Comércio; SBGG - Sociedade Brasileira de Geriatria e Gerontologia; ANG - Associação Nacional de Gerontologia; COBAP - Confederação Brasileira de Aposentados e Pensionistas.

3 In: I Conferência Internacional de Tecnologia Social, Anhembi/SP, 20/11/2004. Palestra de abertura.

4 Tal conselho é responsável pela fiscalização e acompanhamento da PNI em âmbito nacional, sendo composto por membros do corpo técnico do Estado e dos ministérios e por integrantes das organizações representativas da velhice. Cf. Santos (1998).

5 Dita o Art. 10, da Lei 8.842/94: "A PNI tem por objetivo assegurar os direitos sociais do idoso, criando condições para promover sua autonomia, integração e participação efetiva na sociedade". Grifos meus.

6 Schein (1992) divide a cultura de uma organização em três níveis: os artefatos visíveis (facilmente observáveis porque mais aparentes), os valores compartilhados (só obtidos por meio de análise documental e da observação das políticas institucionais) e os pressupostos inconscientes (de mais difícil observação, porque mais profundos, só obtidos por meio de entrevistas com membros-chave da organização).

7 É interessante notar como estão presentes no discurso de aposentados que ainda trabalham uma postura crítica frente à idéia do Estado democrático como representante dos interesses do povo, principalmente em virtude da precariedade das políticas e direitos sociais, conforme mostra a 
pesquisa de Witczak (2003).

8 A palavra aposentadoria, tanto em inglês (retired) quanto em francês (retraite), significa retirar-se, ou seja, diz respeito ao direito do trabalhador de desfrutar do tempo livre após uma vida toda dedicada ao trabalho. Direito esse que é dever do Estado garantir. Cf. Ramos (2001).

9 O Estado também visa se livrar dos custos relativos principalmente à saúde do idoso, que geralmente necessita de tratamentos mais caros e prolongados, dada a sua maior vulnerabilidade física. Cf. Haddad (1986).

10 A ONU recomendou que os países-membros considerassem o ano de 1982 como o "Ano Nacional do Idoso". Cf. Lopes (2000).

11 Cf. Barros (1999), Mendonça (1999) e Peppe (1999).

12 Cf. Haddad (1986).

13 Cf. Lopes (2000).

14 Cf. Borges (2003).

15 Cf. página na internet: <http://www.cobap.hpg.ig.com.br> Consultada em 27/01/2004.

16 Cf. Haddad (2001).

17 Lei $4.227 / 02$.

18 Lei $10.741 / 03$.

19 Lei 8.842/94, Art. 10.

20 Lei $4.227 / 02$, Art. 3o, parágrafo I.

21 Lei 4.227/02, Art. 3o, parágrafo VI.

22 “Comentários ao Estatuto do Idoso”, Estatuto do Idoso, Câmara Municipal de Campinas/SP, 2004, p. 01 .

23 Texto escrito pela Profa. Dra. Anita Liberalesso Neri, Coordenadora do mestrado em Gerontologia Social da Faculdade de Educação da UNICAMP, por correio eletrônico, em 26/08/2003, respondendo a um questionamento meu acerca dos reais protagonistas das mobilizações que resultaram na PNI. Entre colchetes, complementação minha.

24 Cf. página na internet: <http://www.ang.org.br/arq02/m01forumpneirj.doc> (consultada em 27/01/2004). Grifos meus.

25 De acordo com Santos (1998), a PNI está subdividida em seis eixos principais de atuação, cuja condução é de competência dos respectivos ministérios, a saber: I. Saúde; II. Educação; III. Trabalho e Previdência Social; IV. Habitação e Urbanismo; V. Justiça; e VI. Cultura, esporte e lazer.

26 Grifos meus.

27 Lei 8.842/94, Art. 10, parágrafo VII, item “c”. Grifos meus. Entre colchetes, complementação minha.

28 Gohn (2000) denomina essas redes como a "modernidade da participação social e política".

29 Bobbio (1994) define cooptação como um termo usado para: "designar o acolhimento, por parte de um grupo dirigente, de idéias, orientações e programas políticos propostos por grupos da oposição, com o fim de eliminar ou reduzir as conseqüências dos ataques vindos de fora” (p. 286).

30 De acordo com Fernandes (1994): “A idéia de um 'terceiro setor' supõe um 'primeiro' e um 'segundo', e nesta medida faz referência ao Estado e ao mercado. A referência, no entanto, é indireta, obtida pela negação - nem governamental e nem lucrativo” (p. 126).

31 Lei $8.842 / 94$, Art. 3o, parágrafo IV.

32 Lei 8.842/94, Art. 4o, parágrafo II. Grifos meus.

33 Cf. Camarano (1999).

34 Lei 8.842/94, Art. 10o, parágrafo IV, itens "b" e "c".

35 "Comentários ao Estatuto do Idoso", de autoria do advogado Luiz Faria e Souza, apud: Estatuto do Idoso, Câmara Municipal de Campinas, 2004, p. 08. 
36 Conforme mostra o Boletim DIEESE, Edição Especial Dia do Trabalho, de maio de 2004, o salário mínimo, em moeda atual, equivalia proporcionalmente a $\mathrm{R} \$ 834,97 \mathrm{em} 1952$ e a $\mathrm{R} \$ 1.036,10 \mathrm{em}$ 1957, até valer R\$259,70 em 2003. Se em 1959 um salário mínimo comprava $85 \mathrm{~kg}$ de carne, $192 \mathrm{~kg}$ de feijão, $202 \mathrm{~kg}$ de arroz e $230 \mathrm{~kg}$ de pão, por exemplo, em 2003 passa a comprar $29 \mathrm{~kg}$ de carne, $78 \mathrm{~kg}$ de feijão, $134 \mathrm{~kg}$ de arroz e $48 \mathrm{~kg}$ de pão. Isso retrata a queda radical no poder de compra do salário mínimo ocorrida em pouco mais de 50 anos.

37 Jornal Correio Popular, 30/03/2004, pág. 02, Primeiro Caderno, “Correio do Leitor”, título do artigo: "Cinema X idosos".

38 Motta (1986) destaca que: "não se pode afirmar que os partidos políticos de vanguarda e os sindicados de trabalhadores tão-somente participam do modo de produção dominante. É preciso ficar claro que o seu papel é duplo e que sua total cooptação pela classe dirigente implicaria sua completa descaracterização e muito provavelmente seu desaparecimento. A classe trabalhadora, bem como outros grupos sociais oprimidos, só sustenta essas organizações à medida que elas permanecem na oposição, por frágil que seja. Acreditar, porém, que tais organizações sejam em si revolucionárias é ignorar a natureza do fenômeno burocrático" (p. 60).

39 De acordo com Demo (1996) a democracia representativa é limitada por restringir os canais de participação política às eleições e ao voto/plebiscito popular, facilmente manipuláveis por meio de marketing eleitoral ou por outras estratégias de convencimento/indução das massas.

40 Cf. também Wood (2003) e Motta (1990).

41 Cf. página na internet: <http://www.cobap.hpg.ig.com.br> (consultada em 27/01/2004) e também os "Comentários ao Estatuto do Idoso", Estatuto do Idoso, Câmara Municipal de Campinas, 2004.

$42 \mathrm{Na}$ "Apresentação" do Estatuto do Idoso, da Câmara Municipal de Campinas, op. cit., o Senador Paulo Paim (PT/RS), ligado à COBAP, ressalta a importância dessas leis para a consolidação da cidadania do idoso e enfatiza o seu papel como principal articulador político na aprovação do Estatuto.

\section{REFERÊNCIAS}

BARROS, Herbert. Políticas do Ministério da Justiça. In: Revista A Terceira Idade SESC. Editorial: "Políticas governamentais de atenção à velhice para o próximo século", n. 17, agosto de 1999.

BELO, Isolda. Vejez y acción política: surge un nuevo movimiento social? Tese de doutorado em Ciências Sociais e Saúde. Universidade de Barcelona, 2002.

BOBBIO, Norberto. Dicionário de Política. Brasilia: UnB, 1994.

.O tempo da memória: de senectude e outros escritos autobiográficos. Rio de Janeiro: Campus, 1997.

BORGES, Maria. Gestão participativa em organizações de idosos. Dissertação de mestrado em Educação. FE-UNICAMP, 2003. 
terceira idade, ação política...

CACHIONI, Meire; Universidades da terceira idade: das origens à experiência brasileira. In: Velhice e sociedade, DEBERT \& NERI (orgs.). Campinas: Papirus, 1999.

CAMARANO, Ana. Muito além dos 60: os novos idosos brasileiros. Rio de Janeiro: IPEA, 1999.

COHN, Amélia. A questão social no Brasil: a difícil construção da cidadania. In: MOTA, Carlos (org.). Viagem incompleta: a experiência brasileira (1500-2000): a grande transação. São Paulo: SENAC, 2000.

DALLARI, Dalmo. O que é participação política. São Paulo: Brasiliense, 1984.

DEBERT, Guita. A invenção da terceira idade e a rearticulação de formas de consumo e demandas políticas. In: Revista Brasileira de Ciências Sociais, vol. 12, n. 34, jun./1997, p. 39-56.

. \& SIMÕES, Júlio A. A aposentadoria e a invenção da 'terceira idade’. In: DEBERT, Guita (org.). Antropologia e velhice. Textos Didáticos IFCH-UNICAMP, n. 13 , jan./1998, p. 29-44.

DEMO, Pedro. Pobreza política. Campinas: Autores Associados, 1996.

DIAS, Edmundo. A liberdade (im)possível na ordem do capital: reestruturação produtiva e passivização. Textos Didáticos IFCH-UNICAMP, n. 29, 1999.

ESTATUTO DO IDOSO, Edição especial da Câmara Municipal de Campinas, 2004.

FERNANDES, Rubem. Privado porém público: o terceiro setor na América Latina. Rio de Janeiro: Civicus, 1994.

FOUCAULT, Michel. Microfísica do poder. Rio de Janeiro: Graal, 1999.

GOHN, Maria. Os Sem-terra, ONGs e cidadania. São Paulo: Cortez, 2000.

GUATTARI, Félix. Revolução molecular: pulsações políticas do desejo. São Paulo: Brasiliense, 1987.

HADDAD, Eneida. O direito à velhice: os aposentados e a previdência social. São Paulo: Cortez, 2001. . A ideologia da velhice. São Paulo: Cortez, 1986. 
LASLETT, Peter. The emergence of the Third Age. Ageing and society, 7:133-160, 1987.

LOPES, Andrea. Os desafios da Gerontologia no Brasil. Campinas: Alínea, 2000.

MENDONÇA, Jurilza; Políticas do Ministério da Previdência e Assistência Social. In: Revista A Terceira Idade SESC. Editorial: "Políticas Governamentais de atenção à velhice para o próximo século", n. 17, 1999.

MONTAÑO, Carlos. Terceiro setor e questão social: crítica ao padrão emergente de intervenção social. São Paulo: Cortez, 2003.

MOTTA, Fernando. Organização e poder: empresa, Estado e escola. São Paulo: Atlas, 1986.

NERI, Anita. Movimento social do idoso. Mensagem enviada por correio eletrônico, <anitalbn@lexxa.com.br>, em 26/08/2003.

PEPPE, Atílio; Políticas do Ministério do Trabalho e Emprego. In: Revista A Terceira Idade SESC. Editorial: "Políticas governamentais de atenção à velhice para o próximo século", n. 17, agosto de 1999.

PERES, Marcos. Velhice, trabalho e cidadania: as políticas da terceira idade e a resistência dos trabalhadores idosos à exclusão social. Tese de doutorado. Faculdade de Educação da USP, 2007.

RAMOS, Paulo. O direito à velhice. Tese de doutorado em Direito Constitucional. PUCSP, 2001.

SÁNCHES, Lucía \& MARTÍNEZ, Luz. Psicologia, identidade e política nas tecnologias de governo neoliberais. In: Psicologia \& Sociedade, 18 (1), 7-14, jan./abr. de 2006.

SANTOS, Laura. As políticas públicas de atenção à velhice. Dissertação de Mestrado em Serviço Social. PUC/SP, 1998.

SCHEIN, Edgar. Organizational culture and leadership. San Francisco: Jossey Bass, 1992.

SCHERER-WARREN, Ilse. Redes e sociedade civil global. Paper apresentado no Seminário de Estudos sobre organizações não-governamentais na América Latina, Cadernos ABONG, 2001. 
SIMÕES, Julio. Entre o lobby e as ruas: o movimento de aposentados e a politização da aposentadoria. Tese de doutorado em Ciências Sociais. IFCH-UNICAMP, 2000.

TRAGTENBERG, Mauricio. Burocracia e ideologia. São Paulo: Ática, 1980.

VIEIRA, Evaldo. Estado e miséria social no Brasil: de Getúlio a Geisel. São Paulo: Cortez, 1987.

WITCZAK, Marcus V. Lazer e trabalho: relação de continuidade na aposentadoria? In: MÜLLER, Ademir \& DACOSTA, Lamartine (orgs.). Lazer e trabalho: um único ou múltiplos olhares? Santa Cruz do Sul/SC: EDUNISC, 2003.

WOOD, Ellen M. Democracia contra capitalismo: a renovação do materialismo histórico. São Paulo: Boitempo, 2003. 